\title{
Evaluating the Characteristics of E-Government Websites in Developing Countries: Jordan as A Case Study
}

\author{
Asst. Prof. Dr. Mohammad Musa Al-Momani \\ Department of Management Information Systems, Faculty of Economics and Administrative Science, Zarqa \\ University, Zarqa 13132, Jordan
}

\begin{abstract}
"This research is funded by the Deanship of Research at Zarqa University/Jordan"
\section{Abstract}

The intensive use of e-government has created new challenges in government websites. Developing countries cannot escape from these challenges. Such challenges may include the quality of e-government websites services, the usability level, the culture of using internet services, the resistance of using new technology, technical limitations, and the response time. Despite the fact that evaluating e-government websites is not a new phenomenon, limited studies have been conducted in developing countries. Jordan, as one of these developing countries, suffers from the limited studies in this topic. In this paper, the researcher evaluated the official site of the Jordanian e-government. Experimental method has been employed as a methodological approach for data collection and analysis. To evaluate the official site of the Jordanian e-government (OSJEG), a considerable number of factors have been presented including: "quality of e-government websites services" as an dependent variable, the "usability level", the culture of using internet, the resistance of using new technology, technical limitations and the response time" as independent variables; Such factors have positive and negative effects over OSJEG. In addition, several documents have been analyzed as a secondary data. Finally, according to the results from this research, this paper suggests several recommendations that aimed to improve the quality of OSJEG. However, a considerable number of weaknesses in OSJEG could be taken into consideration.
\end{abstract}

Keywords: Jordanian e-government, online services, distance services, Information services, electronic government, new usability technology

DOI: $10.7176 / \mathrm{EJBM} / 11-32-05$

Publication date: November $30^{\text {th }} 2019$

\section{Introduction}

Modern information and communication technologies (ICT) have affected human life in many different sectors, and this development has led people to seek easier and faster services. Completing the transactions of government in a quick way is one of challenges to improve the performance of the work of governmental organizations and agencies, and this prompted governments to transform their transactions technically through websites. The Jordanian government as one of the governments in developing countries is seeking to move towards e-government in order to facilitate the completion of transactions for their recipients and to improve the performance of its organizations. To achieve this, the Jordanian government has computerized all its ministries and agencies through the establishment of an integrated e-government site. The idea of the e-government program came as an initiative of his majesty the King of Jordan in 2001 implemented by the Ministry of Communications and Information Technology. Some financial and technical obstacles were forced egovernment services to delay (e-Government, 2018). At the beginning of the year 2018, an integrated egovernment website is launched in order to provide services only through one single government entity so that the service starts and ends in the same entity.

Now the e-government has a centralized website that includes all government organizations and ministries in one integrated website. This site served all the recipient types including citizens, residents, investors and tourists. The intensive use of e-government has created new challenges in government websites (Kirui, Baguma, \& Kiprono, 2016). Developing countries cannot escape from these challenges. Such challenges may include the quality of e-government websites services, the usability level, the culture of using internet services, the resistance of using new technology, technical limitations, and the response time. Despite the fact that evaluating e-government websites is not a new phenomenon, limited studies have been conducted in developing countries. Jordan as one of these developing countries suffers from the limited studies in this topic. Thus, the main aim of this study is to evaluate the characteristics of the official site of the Jordanian e-government (OSJEG). These characteristics have different factors that can affect the e-government website positively or negatively.

\section{Previous Studies}

\subsection{E-government}

Several researchers have given definitions for e-government. According to them, the researcher can summarize e-government definition as taking advantage of information and communication technologies to develop, improve and manage citizens' affairs in an informational way, based on the internet and its tools, according to 
security guarantees for users and the service provider (Oni, Okunoye, \& Mbarika, 2016), (Al-Khouri, 2013). In addition, e-government refers to the use of internet technology as a platform for transfer information, providing services and transacting with citizens, businesses and others, in order to provide electronic services to ensure easy access to government services for all beneficiaries and through several channels (Gronier, Reiter, \& Beck, 2011).

\subsection{Quality of e-government websites services}

Explaining the meaning of quality in e-government websites services depends in many criteria such as website design, reliability, responsiveness, security/privacy, personalization, information, and ease of use (Hien, 2014). According to Alanezi, Kamil, \& Basri, (2010) e-government service quality is defined as "the degree to which an e-government web site facilitates the competent delivery of efficient e-services to help citizens, businesses and agencies in achieving their governmental transactions".

\subsection{E-government Barriers}

There are many e-government barriers that can play a main role in the success or failure of e-government website effectiveness. These barriers can refer to the usability level, the culture of using internet services, the resistance of using new technology, technical limitations and the response time.

2.3.1. Usability level: (privacy and security)

Usability focuses on the acceptance of the user according to their satisfaction of interactions over the website (Humphrey \& Mayoka, 2016). In addition, the privacy and security are important criteria to users. Privacy refers to the guarantee of protection of the information attributed to user, while the security refers to protection, assets, and the control accessing to the information. At the same time, these criteria became the main critical issues in the implementations of e-government websites (Molnar, 2015). In this case, e-government must build bridges of trust with the beneficiaries by giving them guarantees that their information will be safe and there will be no violation of their privacy (Rorissa \& Demissie, 2010), (Wirtz \& Kurtz, 2016).

2.3.2. Culture of using internet services

E-government faced many challenges, and one of these challenges is cultural implications of new technologies. The acceptance of new technology is affected by individual behavior patterns and the availability of technology between them (Gronier, Reiter, \& Beck, 2011). Not all people in developing countries have access to the Internet due to economic conditions that affect the availability of computers or Internet services or lack of skills to deal with technology (Al-Khouri, 2013). Accordingly, some views assume that this may have a negative effect on culture, because it is related to the level of education, social structure, religion and language preventing the use of the e-government systems. (Al-Khouri, 2013), (Humphrey \& Mayoka, 2016), (Wirtz \& Kurtz, 2016).

2.3.3. Resistance of using new technology

The main idea of e-government is converting paper transactions to electronic transactions. Therefore, users must move to electronic platforms to complete their government transactions. But this transition may be reflected negatively on users and employees in the government because of their resistance to use new technologies like egovernment. In order to reduce the resistance of change by employees, the government should clarify the importance of e-government to its employees, and make it clear to them that this transition will not affect their future career. At the same time, the government must promote the idea of e-government among citizens and beneficiaries and raise awareness of its importance because it completes their transactions quickly and safely anytime and anywhere (Development, 2008), (Zhang, Lin, Lin, \& Hsieh, 2008).

2.3.4. Technical limitations

One of the main technical barriers that faced e-government is the information and telecommunication infrastructure, especially in developing countries which lack it. In addition, privacy and security are critical barriers in implementation of e -government to attract citizen concerns (Nabafu \& Maiga, 2012).

Thus, governments should improve their ICT infrastructure by customize part of the government budget to improve services. On the other hand, the government should make deals with private institutions aimed to build a bridge of cooperation between public and private institutions (Zhang, Lin, Lin, \& Hsieh, 2008).

2.3.5. Response time

Response time reflects the skills of qualified personnel; this means that the level of training for government staff should be high, so the government should provide staff with sufficient education and training to use new technology. However, training is an essential condition with an increased rate of change. Therefore, the full use of information and communication technology (ICT) depends on training and learning skills, which are still growing in the governments of developing countries (Wirtz \& Kurtz, 2016), (Zhang, Lin, Lin, \& Hsieh, 2008).

\section{Methodology}

Experimental method has been employed as a methodological approach for data collection and analysis. In addition, several documents have been analyzed as a secondary data in order to evaluated the official site of the 
Jordanian e-government (OSJEG), a considerable number of factors (as shown in figure1) has been presented, which include: "quality of e-government websites services" as dependent variable, and "usability level, culture of using internet, resistance of using new technology, technical limitations and response time" as independent variables; Such factors have positive and negative effects over OSJEG. According to the researcher's evaluation of the official site of the Jordanian e-government (OSJEG), new positive and negative factors come to exist and the researcher will review and discuss them in detail.

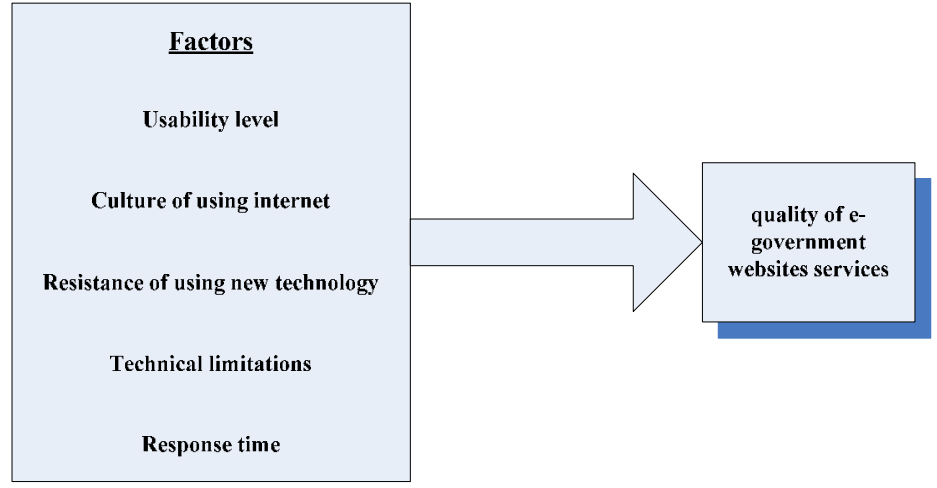

Figure 1: research Model

Many previous studies have tried to focus on the impact of some factors like usability level, culture of using internet, resistance of using new technology, technical limitations and response time on the quality of services provided by e-government.

According to Odat and Khazaaleh, (2012), 41\% of Jordanians are interested in using e-government services, for that, the e-government developing team must improve their programs to achieve all citizens. Moreover, according to Nabafu and Maiga (2012), many factors have affected the quality of e-government services. The researchers have discovered the availability of the e-government website in the interne which includes (usability level, culture of using internet, resistance of using new technology) and how the users can easily find it. The researchers found that the availability of the internet is part of the infrastructure of e-government, thus, providing the service quickly can help to increase the users' attention to accept new technologies (Humphrey \& Mayoka, 2016).

In addition, the citizen sensitization and interactions and ICT infrastructure which include (technical limitations and response time) are played a main role in attracting beneficiaries to use e-government services. In developed countries there are many limitations that can affect the e-government negatively (Rorissa \& Demissie, 2010). So, in order to decrease the limitations and increase the response time, the government should focus in two elements: Training and Sensitization. Employee training should be done throughout the implementation stages, while sensitization can help government to prove to citizens the one who has a negative attitude towards the use of e-government services, and show the benefits they will have when they use it (Nabafu \& Maiga, 2012).

Through this research, the researcher will review his evaluation of the integrated of e-government website in Jordan, by showing the most positive and negative aspects that have been found. Figure 2 shows the home page of OSJEG, the website supported two languages, Arabic and English.

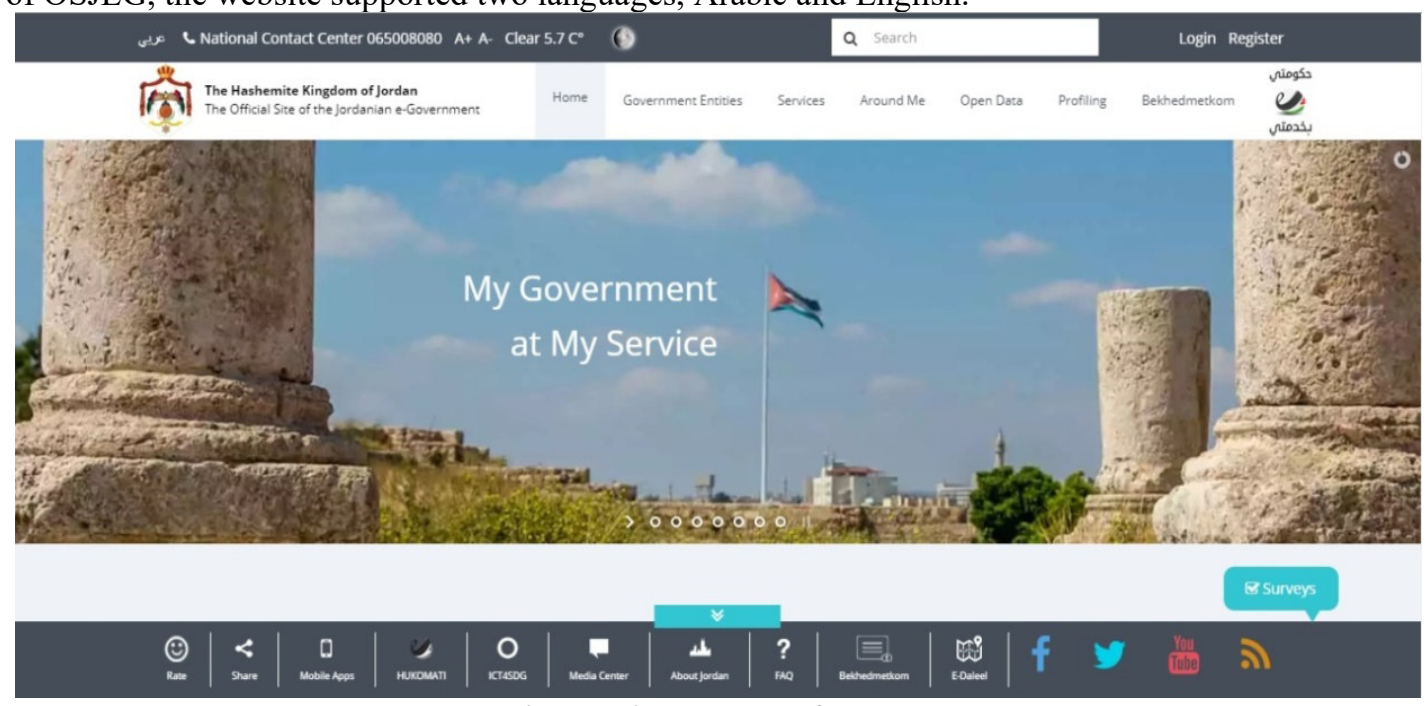

Figure2: home page of OSJEG

The researcher will review a group of aspects in this section related to the design, services and response 
time. According to the evaluated of OSJEG, the design in general is friendly and easy to use. There are two main languages in this website, Arabic and English. After examining both sides separately, the researcher found that the Arabic section is more comprehensive than the English section in terms of the number of services provided. According to OSJEG, there are two kinds of services, e-services and information services. These services are provided to all types of users: citizen, resident, business and visitors. After deep research in the number of services provided by either e-services or information services, the researcher found that the search for services in the Arab side gives more results to the beneficiaries compared to the English side. Table1 shown the compared number of services in two sides related to the types of beneficiaries.

Table1: The compare number of services between Arabic and English sides

\begin{tabular}{|c|c|c|c|}
\hline Website language & Beneficiaries & E-service & Information service \\
\hline \multirow{4}{*}{ Arabic side } & Citizen & 168 & 2526 \\
\cline { 2 - 4 } & Resident & 36 & 768 \\
\cline { 2 - 4 } & Business & 77 & 1501 \\
\cline { 2 - 4 } & Visitors & 26 & 173 \\
\hline \multirow{3}{|c|}{} & 12 & 768 \\
\hline \multirow{3}{*}{ English side } & Citizen & 3 & 183 \\
\cline { 2 - 4 } & Resident & 13 & 449 \\
\cline { 2 - 4 } & Business & 1 & 87 \\
\cline { 2 - 4 } & Visitors & & \multicolumn{1}{|c|}{} \\
\hline
\end{tabular}

According to the results shown in the table above, it can be noticed that the number of services on the Arab side is more than the English side. This result can be positive for citizens as Arabic speakers, but for residents, investors or visitors, may not be useful to them. The English services offered to non-citizens are fewer compared to the same services provided to them by the Arab side, and this can be considered as a weakness in the type of service offered to non-Jordanians. At the same time, the number of services shown in Arab side should be the same number at English side. According to table1, the e-services for visitors in English=1, while in Arabic $=26$, also the information services for visitors in English $=87$ and in Arabic $=173$. This means that the service to visitors and tourists does not meet their needs, while the services in English language must be more than the Arabic language, or equal. So, this can be one of the main weak points in OSJEG.

Moreover, there is an advertisement banner in English side showing some advertisements in Arabic and this does not benefit foreign people. This banner should be fixed to show only English adv. in English side. On the other hand, there are only 31 mobile applications provided for users. This number of applications does not cover all the ministries, institutions and agencies of the government. In addition, most of these applications are supported only by android OS devices not IOS devices.

However, some ministries sites take a long time to load their pages. In addition, the response time for eservices is very low and need to re-implement. Income and sales tax department (as shown in figure3) is a good example as an active department. If you want to start using their e-service, you can't create your account through website; you should visit their nearest office to get your username and password. Also, the tax site does not support English language, so you should add all your information in Arabic only. One of the most common problems that can face users in such a dynamic site is the way to save and submit the files and data that are uploaded in the site. There is only a save button in this site, according to the name of button, the action that should be done here is to save data and files or complete it later. But what happened is the opposite, if you click save that means you submit your treatment and you can edit it. So in this case if you need to edit your files you should contact the department to fix it. The site should give a chance to users to save their files and data to complete it later and submit it later when they finish their treatment. Moreover, the service that is not provided by the OSJEG is the live chat with beneficiaries which help users to contact government employees directly. 


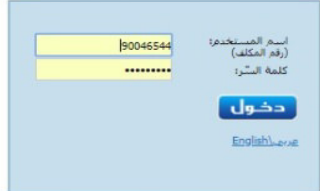

Figure3: Income and sales tax department homepage

\section{Conclusion and recommendations}

In this paper, the researcher evaluated the official site of the Jordanian e-government (OSJEG). The research presents some factors that affect directly the quality of e-government services. Many researchers focused on these factors in order to implement a successful e-government websites. In developing countries; the main problems are in ICT infrastructure, resistance of using new technology and response time. In this search, the researcher evaluated the OSJEG; many negative and positive factors came to existence. The design is easy to use and this is one of the positive factors. Separating the services to e-service and information service makes the site more helpful and useful for users. The services that are provided in Arabic are more than the services provided in English; this is one of the negative factors in OSJEG. The information services should have more details especially for the foreign users, so it will be useful to provide exact information about what information and how to propose them to a particular type of user.

In order to improve the quality of OSJEG, this paper suggests several recommendations as following:

- The government should focus on the websites of its institutions and ministries not only on the integrated e-government website.

- Services that can be obtained when using the English side in website should be the same number of services that can be obtained from the Arabic side.

- E-government should cover and provide all its organizations and ministries services with mobile applications in different operating systems and make it available for users.

- The interface and features of the organizations and ministries websites should be more simple and easy to use.

- The government should increase awareness of the importance of using e-government services.

- OSJEG should add new services like "lives chat" service to communicate directly with beneficiaries.

- The government should raise the level of performance of its employees in order to help them deal with modern technology.

- E-government services should be a full online services, this can be more useful for users and help them to complete their transactions anytime and anywhere without the need to visit the government department.

\section{References}

Alanezi, M. A., Kamil, A., \& Basri, S. (2010). A proposed instrument dimensions for measuring e-government service quality. International Journal of $u$-- and e-- Service, Science and TechnologyService, 3 (4), 1-18.

Al-Khouri, A. (2013). e-Government in Arab Countries: A 6-Staged Roadmap to Develop the Public Sector. Journal of Management and Strategy , 4 (1), 1-28.

Development, B. f. (2008). Electronic Government for Developing Countries. Switzerland: International Telecommunication Union.

e-Government, T. o. (2018, Jan 1). Home page. Retrieved Jan 1, 2019, from The offical site of the Jordanian eGovernment: http://moict.gov.jo/content/eGovernment-Program

Gronier, G., Reiter, S., \& Beck, M. (2011). Quality of service and citizen profiling in e-Government. 11th European Conference on e-Government (ECEG'11). Ljubljana, Slovenia.

Hien, N. M. (2014). A Study on Evaluation of E-Government Service Quality. International Journal of Social, Behavioral, Educational, Economic, Business and Industrial Engineering, 16-19.

Humphrey, A., \& Mayoka, K. (2016). A Framework for Usability of e-Government Services in Developing 
Countries. Global Advanced Research Journal of Social Science , 1-10.

Kirui, E., Baguma, R., \& Kiprono, K. P. (2016). Usability Framework for E-Government Services in Developing Countries. International Journal of Computer Applications (0975 - 8887) , 137 (11), 43-47.

Molnar, T. (2015). Improving Usability of e-Government for the Elderly. The Electronic Journal of $e$ Government, 13 (2), 122-135.

Nabafu, R., \& Maiga, G. (2012). A Model of Success Factors for Implementing Local E-government in Uganda. Electronic Journal of e-Government, 10 (1), 31-46.

Odat, A., \& Khazaaleh, M. (2012). E-Government Challenges and Opportunities: A Case Study of Jordan. IJCSI International Journal of Computer Science , 9 (5), 361-367.

Oni, A., Okunoye, A., \& Mbarika, V. (2016). Evaluation of E-Government Implementation: TheCase of State Government Websites in Nigeria. The Electronic Journal of e-Government, 14 (1), 48-59.

Rorissa, A., \& Demissie, D. (2010). An analysis of African e-Government service websites. Government Information Quarterly, 1-9.

Wirtz, B., \& Kurtz, O. T. (2016). Citizen preferences toward e-government city portals - an empirical analysis of full online, mobile and social media services. International Public Management Review , 17 (1), 1-20.

Zhang, Y., Lin, Z., Lin, Q., \& Hsieh, C.-t. (2008). The Readiness for and Current Status of E-Government in China. Journal of International Technology and Information Management , 17 (1), 75-84.

Assist. Prof. Dr. Mohammad Al-Momani was born in Jordan in 1984. He graduated from Al-Balqa Applied University in 2006 with a B.S. in Computer Information Systems (CIS) and in M.S. degree in CIS in 2009 from Near East University (Cyprus). In 2014, he received his $\mathrm{PhD}$ in Management Information Systems (MIS) from Girne American University (Cyprus). Dr. Al-Momani is now an Assistant Professor at Zarqa University (Jordan) and is currently serving as a head of MIS department. His research interests focus on Networks, Databases, Online learning and Information systems and Sciences. 